\title{
Pain and anxiety in office histeroscopy
}

\author{
Mayanna Oliveira Rolim \\ (D) Ana Luiza Ramos Morais ${ }^{1}$ \\ (iD) Camila Sampaio Nogueira ${ }^{2}$ \\ (D) Maria do Socorro Monte de Araujo ${ }^{3}$ \\ (iD) Denise Vasconcelos de Moraes ${ }^{1}$ \\ (iD) Raquel Autran Coelho ${ }^{4}$
}

\begin{abstract}
1. Médica na Maternidade-Escola Assis Chateubriand, Universidade Federal do Ceará, Fortaleza, CE, Brasil.
2. Estudante de Medicina na Faculdade de Medicina, Universidade Federal do Ceará, Fortaleza, CE, Brasil. 3. Enfermeira na Maternidade-Escola Assis Chateubriand, Universidade Federal do Ceará, Fortaleza, CE, Brasil. 4. Professora Associada na Faculdade de Medicina, Universidade Federal do Ceará e Unichristus, Fortaleza, CE, Brasil.
\end{abstract}

http://dx.doi.org/10.1590/1806-9282.66.12.1633

\section{SUMMARY}

BACKGROUND: Anxiety is almost always present before medical interventions and may play a role in pain perception. We aim to evaluate factors associated with pain intensity reported by patients submitted to Office Hysteroscopy $(\mathrm{OH})$.

METHODS: Cross-sectional observational study, with data from April to November 2015. It included patients attended at the Assis Chateaubriand Maternity School (MEAC/UFC) with an indication of office hysteroscopy. Before the examination, the patients answered a validated questionnaire about anxiety (STAI). After the examination, women answered the Visual Analogue Scale (VAS). The data were analyzed using the Statistical Package for the Social Sciences (SPSS) 15.0, with Spearman correlation, Mann-Whitney U-test, and analyses of variance.

RESULTS: 252 patients were included, with a mean age of 45.7 years, of whom $29 \%$ were postmenopausal (mean pain 5.5 ) and $71 \%$ were in menacme (mean pain 5.1) ( $p=0.258)$. The anxiety trait and state showed a significant influence on the pain scale ( $p<0.001$ and $p=0.001$ ), but age or endometrial sample did not. $27 \%$ of the patients were nulliparous. Less pain was associated with the number $(p=0.01)$ and vaginal $(p=0.005)$ of deliveries. The main indication for the procedure was abnormal uterine bleeding (54.4\%).

CONCLUSION: $\mathrm{OH}$ may be associated with moderate but tolerable discomfort. There was a significant correlation between higher scores on the pain scale and anxiety. There was evidence of reduced pain with parity and type of delivery, but not with reproductive age or endometrial biopsy.

KEYWORDS: Pain Measurement. Manifest Anxiety Scale. Hysteroscopy.

\section{INTRODUCTION}

Hysteroscopy represents the gold standard for the evaluation of the uterine cavity and adequate endometrial sampling due to its minimal invasiveness and high diagnostic success rate ${ }^{1}$. Hysteroscopy can be performed in the outpatient department, without anesthesia. Office hysteroscopy $(\mathrm{OH})$ is becoming increasingly popular, with the use of the minihysteroscope with a vaginoscopic and no-touch approach, leading to less painful and better-tolerated examinations and even operations ${ }^{2,3}$.

In general, this procedure is very safe and well-tolerated by patients. Nevertheless, thinner

DATE OF SUBMISSION: 12-Jul-2020

DATE OF ACCEPTANCE: 25-Jul-2020

CORRESPONDING AUTHOR: Raquel Autran Coelho

Departamento de Saúde da Mulher, da Criança e do Adolescente (UFC)

Rua Professor Costa Mendes, 1608, 50 andar, Fortaleza, CE, Brasil - 60430-140

Tel/Fax: +55 85 3366-8041

E-mail: raquelautrancp@gmail.com 
scopes do not guarantee a painless procedure, as some women still report significant suffering. Yang and Vollenhoven ${ }^{4}$ reported that pain is the most common reason for failing to perform $\mathrm{OH}$. Potential factors associated with pain perception during this procedure include the diameter of the scope, medical experience, age, and anxiety of the patient. Therefore, some factors may contribute to the selection of women candidates for analgesia, due to the greater susceptibility to severe pain during the outpatient procedure ${ }^{5}$.

Anxiety is almost always present before medical interventions and may play a role in pain perception. There seems to be a positive association between the anxiety level and visual analog scale (VAS) pain reporting, and in some cases, nervousness may lead to catastrophizing (exaggerated negative orientation toward pain stimuli). There are some validated scales widely used to measure the general anxiety level. Nonetheless, the effect of anxiety on pain perception during $\mathrm{OH}$ has not been well-defined yet ${ }^{3,6,7}$.

In view of the lack of regional studies on the tolerance of $\mathrm{OH}$, we sought to evaluate factors associated with the level of pain reported by patients submitted to $\mathrm{OH}$ in a tertiary hospital in the northeast of Brasil, as well as to observe the influence of women's anxiety during the examination.

\section{METHODS}

This is an observational, cross-sectional, descriptive study based on data collected from April 2015 to November 2017. The study population consecutively included all women who attended the gynecology department of the Assis Chateaubriand Maternity School (MEAC), Federal University of Ceará (UFC), with an indication for $\mathrm{OH}$. Patients with contraindications for the examination (gestation, cervicitis, genital bleeding, and acute pelvic inflammatory disease) were excluded, in addition to those who had previously had analgesics or any other cervical preparation, were under 18 years of age, were intellectually incapable of answering the questionnaire, or voluntarily manifested the desire not to participate in the study.

Clinical and demographic information were obtained from each participant during a medical interview. Immediately before the examination, the patients answered a validated self-assessment questionnaire about anxiety (STAI) ${ }^{8}$, through the reduced Portuguese version of Spielberguer STAIStatic Anxiety Inventory (STAI) ${ }^{9,10}$. The STAI was introduced in 1970 and revised in 1983, with questions on a 1 to 4 Likert scale, and is among the most widely researched measure of general anxiety, available in many different languages. It gives a score of 20-80, and the higher the score, the greater the anxiety. One of its particularities is to differentiate the state anxiety (STAI-S), which evaluates the current state of anxiety, asking how women feel "right now," from a patient's trait anxiety (STAI-T), which evaluates relatively stable aspects of propensity to be anxious. The short-form version consists of 6 self-reported items with high internal consistency alpha coefficients.

All the examinations were carried out in an ambulatory setting without analgesia or anesthesia, during in the first phase of the menstrual cycle, for women in the menacme, by surgeons with different experiences in $\mathrm{OH}$. Participants were positioned in the gynecological position. A $2.9 \mathrm{~mm}$ rigid hysteroscope was introduced under direct vision into the uterine cavity (Karl Storz, Tuttlingen, Germany). The distension medium used was $0.9 \%$ saline solution with a continuous flow and intrauterine pressure of $75 \mathrm{mmHg}$, controlled by an electronic pump (Karl Storz Endoskope ${ }^{\circledR}$, Hysteromat, Germany). The image was transmitted in real-time to a monitor, allowing the patient to watch the examination. Endometrial biopsies were performed with a Novak curette, if necessary. OH lasted between 15 to 30 minutes.

After the procedure, women answered the VAS, a one-dimensional instrument for the evaluation of pain intensity. Pain rating according to a $0-10 \mathrm{~cm}$ VAS (0-3 mild pain, 4-7 moderate pain, 8-10 severe pain) is recommended by World Health Organization ${ }^{11}$.

Quantitative data are presented as mean and standard deviation. Spearman's correlation, Mann-Whitney U-test, and analyses of variance were used to verify the relationship between the intensity of pain perception and other variables in the sample. p-values $<0.05$ were considered significant. All statistical analyses were performed with the software Statistical Package for Social Sciences (SSPS) 22.

This work was approved by the Research Ethics Committee - CEP of the Assis Chateaubriand Teaching Maternity Hospital under protocol 934.442 of 1/14/2015. The patients signed a Free and Informed Consent Form to participate in the study. 


\section{RESULTS}

The study included 252 patients, with a mean age of $45.7 \pm 10.8$ years old, and a mean pain of $5.6 \pm 3.2$, according to the VAS. $29 \%$ of women were post-menopausal. Age and menopausal status were not associated with mean pain ( $\mathrm{p}=0.99$ and 0.26 , respectively). $27 \%$ of the patients were nulliparous. Pain was associated with the number $(\mathrm{p}=0.01)$ of deliveries. Regarding the type of delivery, $51.1 \%$ of women had at least 1 vaginal delivery and reported less pain $(\mathrm{p}=0.005)$ (Table 1)

TABLE 1. MEAN PAIN SCORE AFTER OH, ACCORDING TO PATIENT CHARACTERISTICS.

\begin{tabular}{l|l|l} 
Characteristics & Pain (VAS O - 10) & P-value \\
\hline Menopause & $5.5 \pm 3.0$ & 0.258 \\
\hline Yes & $5.1 \pm 2.9$ & \\
\hline No & $4.3 \pm 2.8$ & $0.005^{\star}$ \\
\hline Previous vaginal delivery & $5.9 \pm 2.9$ & \\
\hline Yes & & \\
\hline No & $5.1 \pm 2.8$ & 0.374 \\
\hline Endometrial biopsy & $5.5 \pm 3.3$ & \\
\hline Yes &
\end{tabular}

Note: Data expressed as mean \pm standard deviation; VAS: Visual Analogic Scale Mann-Whitney $\mathrm{U}$ test; ${ }^{*}$ Significance considered $\mathrm{p} \otimes 0.05$

The main indications for the procedure were abnormal uterine bleeding (54.4\%) and endometrial thickening (31.4\%). $66.9 \%$ of patients underwent an endometrial biopsy with a mean pain of $5.1 \pm 2.8$. There was no correlation between the biopsy procedure and the VAS $(p=0.37)$. There were no cases of carcinoma in the samples.

Pain perception during hysteroscopy was categorized into three groups according to VAS (slight, moderate or intense pain): (1) <4, with 105 cases (41.7\%); (2) $\geq 4$ and $\leq 7$, with 75 cases (29.8\%); and (3) $>7$, with 72 cases $(28.6 \%)$.

Mean state anxiety (STAI-S) was $47.6 \pm 0$, while mean trait anxiety (STAI-T) was $43 \pm 15$, on a 0 to 80 scale. The pain reported by VAS was correlated to both scales of anxiety (Table 2).

There was a positive correlation between the VAS and STAI-S $(r=0.21, p=0.01)$ and between the VAS and STAI-T $(r=0.28, p<0.001)$.

\section{DISCUSSION}

The mean pain reported by the patients in this study, according to the VAS, was 4.5, thus considered mild to moderate, but with tolerable discomfort. The main complaint of patients submitted to $\mathrm{OH}$ is pain, a factor that limits the success of the examination ${ }^{4}$. The pain scale used is quick to apply and easily understood by the patient. For the VAS evaluation, scores of 2.5 to 3 were considered the upper limit score for mild pain, and scores above the upper limit of the VAS of 6.5 to 7 defined pain as severe ${ }^{12}$. However, as a one-dimensional instrument, it only analyzes the intensity of pain. The mean pain index values shown for $\mathrm{OH}$ have conflicting results in different populations and regions of the world, ranging from 1.8 to $6.02^{7,8,13-18}$. This may be due to different service experiences combined with the higher prevalence of normal births in some countries in relation to the Brazilian population.

In previous studies with mixed populations and different indications of hysteroscopy, a wide range of women referring to a VAS $\geq 4$ was observed, varying from $21 \%$ to $88 \%^{17,19}$. We found $58.4 \%$ of women with a VAS $\geq 4$. Several factors can influence these results, including reproductive status, distension medium, and surgeon experience. Such findings confirm that hysteroscopy is a painful examination in a considerable number of cases. Patients may experience pain as a result of physical stimuli such as intrauterine pressure and manipulation. However, pain is subjective; its perception is modulated by states of mood and emotion ${ }^{13}$. In fact, patient support has been linked to less pain and anxiety ${ }^{6,20,21}$.

TABLE 2. COMPARISON OF PAIN IN GROUPS OF PATIENTS UNDERGOING HYSTEROSCOPY AFTER STRATIFICATION OF PAIN INTENSITY LEVELS IN SUBGROUPS: SLIGHT, MODERATE, OR INTENSE

\begin{tabular}{|c|c|c|c|c|}
\hline \multirow[b]{2}{*}{ Variables } & \multicolumn{3}{|c|}{ Pain intensity } & \multirow[b]{2}{*}{$p$} \\
\hline & $\begin{array}{l}\text { Slight pain }(0-3) \\
N=105\end{array}$ & $\begin{array}{l}\text { Moderate pain (4-7) } \\
\mathrm{N}=75\end{array}$ & $\begin{array}{l}\text { Intense pain }(8-10) \\
\mathrm{N}=72\end{array}$ & \\
\hline Age (years) & $46.1 \pm 9.9$ & $44.8 \pm 11.2$ & $45.9 \pm 10.8$ & 0.857 \\
\hline STAI-S & $43.8 \pm 15.5$ & $45.9 \pm 12.6$ & $51.2 \pm 14.0$ & $0.009^{\star}$ \\
\hline STAI-T & $38.6 \pm 14.6$ & $43.8 \pm 13.6$ & $48.9 \pm 15.5$ & $<0.001^{*}$ \\
\hline
\end{tabular}

Note: Data expressed as mean \pm standard deviation ANOVA; ${ }^{*}$ Significance considered $p \otimes 0.05$ 
In this study, the anxiety trait and state showed a significant correlation with the pain scale completed after the procedure. The mean STAI-S and STAI-T were above 40, which is higher than the score of the Brazilian female population (mean: 35.7 ) and suggests a moderate level of anxiety before the examination, similar to other studies. It has been suggested that scores of 39 to 55 are indicative of clinically significant anxiety 7,12,20,22.

Patients' anxiety about medical appointments may influence the perception of pain, the success rate, and satisfaction ${ }^{13,23}$. The effect of the anxiety state on pain has been suggested in some previous studies ${ }^{7,21}$, but not in others ${ }^{20,22}$. It is difficult to explain these conflicting results due to the heterogeneity of the studies and population, but it is important to notice that there is a high prevalence of women presenting moderate levels of anxiety before hysteroscopy.

Based on this context, efforts should be made to identify predictors or interventions that may assist in identifying individuals at greater risk of anxiety and preventing/limiting anxiety and its consequences. Providing a greater degree of comfort during the examination, such as by offering the patient a detailed explanation of the method, for example, can be an important pain reduction strategy.

Parity and previous vaginal delivery were associated with less pain in $\mathrm{OH}$ in this study. There is no consensus on the history of normal delivery as a variable capable of determining pain reduction. It has shown a great impact on pain reduction in a clinical trial with multivariate analysis ${ }^{17}$. In Brasil, a country with a high cesarean rate in the health system, the use of strategies capable of reducing pain regardless of the obstetric history has a good acceptance ${ }^{20}$.

Although there is evidence that genital atrophy may make it difficult to perform the examination, the findings of this study do not support such claims ${ }^{17}$. Age did not influence the pain level among the women analyzed. The main indications for hysteroscopy in the present study were abnormal uterine bleeding, endometrial thickening, and myomatosis, and most of the women were pre-menopausal.

The performance of a guided biopsy can be as painful as or even more uncomfortable than the exam itself $f^{4,5}$. The endometrial biopsy was performed with Novak and the material was collected in a non-directed way, which could be a contributing factor for pain. There was no association, however, between the biopsy and the pain scale among the women studied.
The examination was carried out in a University Hospital by resident physicians in gynecology with a varied learning curve, guided by supervising physicians, which inherently leads to a variation in the performance. Other studies found that experienced surgeons are a protective factor for pain perception during diagnostic hysteroscopy ${ }^{20,24}$. Factors such as technical ability may be correlated with the degree of anxiety and pain during hysteroscopy ${ }^{3}$. Another possible limitation is the lack of information about women's history of chronic pelvic pain and dysmenorrhea as a predictive factor of pain during hysteroscopy. Besides that, the questionnaire applied could lead to bias in the study when associated with the low cognitive level of some patients.

Office Hysteroscopy was associated with moderate but tolerable discomfort. There was a significant correlation between anxiety and higher scores on the pain scale. There was evidence of a relationship between reduced pain and parity and type of delivery, but not with reproductive age or endometrial biopsy procedure. The early identification of possible predictors of pain could trigger interventions to improve analgesia and reduce anxiety in patients who will undergo $\mathrm{OH}$.

\section{Conflicts of interest}

The authors have no conflicts of interest, be it political, economic, regarding resources for carrying out the research, or intellectual property.

\section{Acknowledgments}

We would like to thank the directors of the Maternidade-Escola Assis Chateaubriand/UFC for granting us permission to carry out this study.

\section{Author's Contribution}

Mayanna Rolim; Raquel Coelho; Camila Nogueira 1. Substantial contributions to the study concept and design, data collection or analysis and interpretation; 2. Writing of the article or relevant critical review of the intellectual content and 3. Final approval of the version to be published.

Ana Luiza Morais; Maria do Socorro Araujo; Denise de Moraes 1. Substantial contributions to the study concept and design, data collection or analysis and interpretation; 2. Final approval of the version to be published. 


\section{RESUMO}

INTRODUÇÃO: A ansiedade está quase sempre presente antes de intervenções médicas e pode desempenhar um papel importante na percepção da dor. Buscou-se avaliar os fatores associados à intensidade da dor relatados pelos pacientes submetidos a histeroscopia ambulatorial (HA).

MÉTODOS: Estudo observacional transversal, com dados de abril a novembro de 2015. Foram incluídas pacientes atendidas na Maternidade Escola Assis Chateaubriand (Meac/UFC) com indicação de HA. Antes do exame, as pacientes responderam a um questionário validado sobre ansiedade (IAM). Após o exame, as mulheres responderam à Escala Visual Analógica (EVA). Os dados foram analisados no Statistical Package for the Social Sciences (SPSS) 15.0, com correlação de Spearman, teste U de Mann-Whitney e Anova.

RESULTADOS: Foram incluídas 252 pacientes, com idade média de 45,7 anos, das quais 29\% estavam na pós-menopausa (dor média $5,5)$ e $71 \%$ eram menacme (dor média 5,1) ( $p=0,258)$. O traço e o estado de ansiedade mostraram influência significativa na escala de dor ( $p<0,001$ e $p=0,001$ ). Vinte e sete por cento das pacientes eram nulíparas. Menor dor foi associada ao número ( $p=0,01)$ e tipo vaginal ( $p=0,005)$ de partos. A principal indicação para o procedimento foi sangramento uterino anormal (54,4\%); $66,1 \%$ necessitaram de amostra endometrial.

CONCLUSÕES: A HA pode estar associada a um desconforto moderado, mas tolerável. Houve correlação significativa entre escores mais altos na escala de dor e ansiedade, menor paridade, mas não com idade reprodutiva ou procedimento de biópsia endometrial.

PALAVRAS-CHAVE: Medição da dor. Escala de ansiedade manifesta. Histeroscopia.

\section{REFERENCES}

1. Gkrozou F, Dimakopoulos G, Vrekoussis T, Lavasidis L, Koutlas A, Navrozoglou I, et al. Hysteroscopy in women with abnormal uterine bleeding: a meta-analysis on four major endometrial pathologies. Arch Gynecol Obstet. 2015;291(6):1347-54.

2. Paulo AAS, Solheiro MHR, Paulo COS, Afreixo VMA. What proportion of women refers moderate to severe pain during office hysteroscopy with a mini- hysteroscope? A systematic review and meta-analysis. Arch Gynecol Obstet. 2016;293(1):37-46.

3. Cicinelli E, Rossi AC, Marinaccio M, Matteo M, Saliani N, Tinelli R. Predictive factors for pain experienced at office fluid minihysteroscopy. J Minim Invasive Gynecol. 2007;14(4):485-8.

4. Yang J, Vollenhoven B. Pain control in outpatient hysteroscopy. Obstet Gynecol Surv. 2002;57(10):693-702.

5. New EP, Sarkar P, Sappenfield E, Mikhail E, Plosker S, Imudia AN. Comparison of patients' reported pain following office hysteroscopy with and without endometrial biopsy: a prospective study. Minerva Ginecol. 2018;70(6):710-5.

6. Gambadauro P, Navaratnarajah R, Carli V. Anxiety at outpatient hysteroscopy. Gynecol Surg. 2015;12(3):189-96.

7. Kokanali MK, Cavkaytar S, Guzel Al, Topçu HO, Eroğlu E, Aksakal O, et al. Impact of preprocedural anxiety levels on pain perception in patients undergoing office hysteroscopy. J Chin Med Assoc. 2014;77(9):477-81.

8. Marteau TM, Bekker H. The development of a six-item short-form of the state scale of the Spielberger State-Trait Anxiety Inventory (STAI). Br J Clin Psychol. 1992;31(3):301-6.

9. Spielberger CD. State-trait anxiety inventory. In: Weiner IB, Craighead WE, eds. The Corsini encyclopedia of psychology. $4^{\text {th }}$ ed. Hoboken: John Wiley \& Sons; 2010.

10. Fioravanti-Bastos ACM, Cheniaux E, Landeira-Fernandez |. Development and validation of a short-form version of the Brazilian State-Trait Anxiety Inventory. Psicologia: Reflexão e Crítica. 2011;24(3):485-94.

11. World Health Organization. WHO pain ladder with pain management guidelines 2010. [cited 2020 Jul 3]. Available from: www.who.int/cancer/ palliative/painladder/en/

12. Pegoraro A, Santos ME, Takamori JT, Carvalho WAP, Oliveira R, Barbosa $\mathrm{CP}$, et al. Prevalence and intensity of pain during diagnostic hysteroscopy in women attending an infertility clinic: analysis of 489 cases. Einstein. 2020;18:1-7.
13. Carta G, Palermo P, Marinangeli F, Piroli A, Necozione S, De Lellis V, et al. Waiting time and pain during office hysteroscopy. I Minim Invasive Gynecol. 2012;19(3):360-4.

14. Paulo AA, Pipa A, Andrade CR, Oliveira R, Afreixo VM. Pain, anxiety and patient satisfaction in office hysteroscopy, is there a link? Are patient satisfaction questionnaires reliable? Int | Reprod Contracept Obstet Gynecol. 2017:5(3):642-50

15. Gambadauro P, Magos A. Pain control in hysteroscopy. Finesse, not local anaesthesia. BMJ. 2010;340:c2097.

16. Carvalho Schettini IA, Ramos de Amorim MM, Ribeiro Costa AA, Albuquerque Neto LC. Pain evaluation in outpatients undergoing diagnostic anesthesia-free hysteroscopy in a teaching hospital: a cohort study. I Minim Invasive Gynecol. 2007;14(6):729-35.

17. Angioli R, De Cicco Nardone C, Plotti F, Cafà EV, Dugo N, Damiani P, et al. Use of music to reduce anxiety during office hysteroscopy: prospective randomized trial. | Minim Invasive Gynecol. 2014;21(3):454-9.

18. Capmas P, Pourcelot AG, Giral E, Fedida D, Fernandez H. Office hysteroscopy: a report of 2402 cases. | Gynecol Obstet Biol Reprod (Paris). 2016;45(5):445-50.

19. Sharma |B, Aruna |, Kumar P, Roy KK, Malhotra N, Kumar S. Comparison of efficacy of oral drotaverine plus mefenamic acid with paracervical block and with intravenous sedation for pain relief during hysteroscopy and endometrial biopsy. Indian J Med Sci. 2009;63(6):244-52.

20. Morgan M, Dodds W, Wolfe C, Raju S. Women's views and experiences of outpatient hysteroscopy: implications for a patient-centered service. Nurs Health Sci. 2004;6(4):315-20.

21. Campo R, Molinas CR, Rombauts L, Mestdagh G, Lauwers M, Braekmans $P$, et al. Prospective multicentre randomized controlled trial to evaluate factors influencing the success rate of office diagnostic hysteroscopy. Hum Reprod. 2005;20(1):258-63.

22. Keyhan S, Munro MG. Office diagnostic and operative hysteroscopy using local anesthesia only: an analysis of patient reported pain and other procedural outcomes. I Minim Invasive Gynecol. 2014;21(5):791-8.

23. Pluchino N, Ninni F, Angioni S, Artini P, Araujo VG, Massimetti G, et al. Office vaginoscopic hysteroscopy in infertile women: effects of gynecologist experience, instrument size, and distention medium on patient discomfort. J Minim Invasive Gynecol. 2010;17(3):344-50.

24. Freitas Fonseca M, Sessa FV, Resende |A |r, Guerra CG, Andrade CM |r, Crispi CP. Identifying predictors of unacceptable pain at office hysteroscopy. Jinim Invasive Gynecol. 2014;21(4):586-91. 